Journal of

Applied

addenda and errata

Crystallography

ISSN 1600-5767

\title{
An optical chopper for generation of short X-ray pulses to allow in-house time-resolved photocrystallography. Corrigendum
}

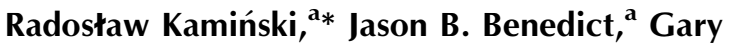 \\ Nottingham $^{\mathrm{b}}$ and Philip Coppens ${ }^{\mathrm{a} *}$
}

a Department of Chemistry, University at Buffalo, The State University of New York, Buffalo, NY 14260-3000, USA, and ' College of Arts and Sciences, University at Buffalo, The State University of New York, Buffalo, NY 14260-3000, USA.

Correspondence e-mail: radoslaw@buffalo.edu,coppens@buffalo.edu

In the paper by Kamiński et al. [J. Appl. Cryst. (2014), 47, 1765-1768], Jason B. Benedict is missing from the list of authors. The complete list of authors should be Radosław Kamiński, Jason B. Benedict, Gary Nottingham and Philip Coppens.

\section{References}

Kamiński, R., Nottingham, G. \& Coppens, P. (2014). J. Appl. Cryst. 47, 17651768 . 